\title{
Compliance to Community Infection Control Standards during the COVID-19 Pandemic: An Integrative Review
}

\author{
Romeo M. Sanchez II ${ }^{1}$, Gevin R. Soriano ${ }^{2}$, Sheree Ann A. Ortua ${ }^{3}$, \\ Alicia A. Tuazon ${ }^{4}$ \\ ${ }^{1-4}$ Doctor of Philosophy in Nursing Science Students, St. Paul University Philippines \\ Corresponding Author: Romeo M. Sanchez II
}

\begin{abstract}
This integrative literature review was conducted to assess the compliance to community infection control standards during the Covid-19 pandemic. As countries struggle to contain Covid-19 and its effects on social and economic aspects of life, non-pharmacologic interventions are seen as a viable option to mitigate the pandemic. This review aims to explore the level and extent to which the community perform health practices as well as the factors that affect compliance to these preventive measures. A systematic search of literatures that was published during 2020 and 2021 that addressed the health practice towards mitigating this pandemic as well as their compliance was included in this literature review. Whittemore and Knafl's procedure in conducting integrative literature review was utilized. After critical appraisal of these literatures using the Quality Assessment Tool for Qualitative Studies, 4 studies were then included. Overall, studies reveal that health practices to mitigate Covid19 are highly practiced. This finding is relation to the adequate knowledge of the community towards these preventive measures. However, despite having enough knowledge and awareness on the various information regarding the existence of the Coronavirus disease, the people in the community still need to enhance their knowledge along COVID 19 issues to minimize the risk of having the virus.
\end{abstract}

Key Words: Compliance, Community, Infection Control Standards, Covid-19

\section{BACKGROUND}

At the moment, Covid-19 remains a threat to global health. Measures to mitigate this disease have been undeniably difficult. Despite intense efforts in terms of advancement in health technology and research, confirmed cases of Covid-19 continue to escalate thus putting too much strain on the already overwhelmed healthcare systems of different countries around the world as healthcare is undoubtedly in crisis in both access to and quality of care [1]. To date, there have been $226,844,344$ confirmed cases of this disease, 4,666,344 of which are deaths, according to the World Health Organization [2]. Aside from its ill-effects on a person's health, the devastating effects of Covid-19 also go around the economic and social aspects of life [3]. Attributable to effects of this disease, preventive measures are undertaken to mitigate Covid-19. These preventive measures include infection prevention, early viral detection, and identification of successful treatment protocols as these interventions provide the best approach in controlling disease spread [4]. In this review, the discussion revolves around the compliance to community infection control standards in this time of pandemic, as infection prevention measure.

The currently ongoing global pandemic of coronavirus disease that started in 2019 (COVID-19) is caused by severe 
acute respiratory syndrome coronavirus 2 (SARS-CoV-2) [5]. The virus has overcome geographical barriers achieving a remarkable proliferation, resulting in different countries to use public health protocols to control the spread of the virus to avoid a collapse of their health systems. These strategies include isolation of cases, hand hygiene, respiratory etiquette, use of homemade facemasks, social distancing, measures such as closing of schools/ universities, banning large events or mass gatherings, restricting travel/ public transportation, stay at home, and total lockdown except to buy food or medicines or to seek healthcare [6]. This total lock down measures has raised a variety of reactions among the population, causing anguish, and massive fear. In recent times, the lockdown rules are gradually being eased off across cities of the world, with generality of activities returning to normalcy. With the easing of lockdown, the government effort has become less forceful. There is a loosening of prevention measures by the population, a denial of reality and the impossibility of enforcing restrictions. The non-compliance and, to some extent the disinterest of certain human groups in relation to these regulations is alarming [7].

Covid-19 has brought the basics back in terms of prevention and control of communicable diseases. Infection prevention and control is considered to be universally relevant component of all health systems. It affects the health and safety of both healthcare providers and their clients [8]. The importance of adherence to infection control in relevant in this present times. Covid-19 can be transmitted through direct, indirect, or close contact with infected people through infected secretions such as saliva and respiratory secretions or their respiratory droplets, which are expelled when an infected person coughs, sneezes, talks, or sings [9]. With the surge of SARS-CoV-2 variants of interest and concern, the performance of standard infection control practices is regarded as of utmost importance. The B.1.617.2 variant, also known as the Delta variant, tend to become more transmissible compared with other variants [10], thus creating a surge of new Covid-19 cases in the community setting. With this, stringent measures must be done in observing infection control standards with the aim of flattening the epidemic curve thus reducing the mortality and morbidity across different geographic communities.

World Health Organization defines Infection prevention and control (IPC) as a practical, evidence-based approach preventing patients and health workers from being harmed by avoidable infections [11]. Infection control measures that are practiced in the community setting prevent transmission of infection from one person to the other. When done appropriately, may serve as first line of defense in slowing down the spread of infectious diseases. Meanwhile, Center for Disease Control and Prevention (CDC) define Community interventions for Infection Control as series of practices that prevent and slow the spread of pandemic infectious diseases in communities through non-pharmaceutical interventions [9]. The importance of Infection Control is undeniable especially in today's global outlook where countries struggle to contain the disease as evident by increasing number of mortality and morbidity. By enabling the communities to take necessary action based on existing principles on infection control, decline in the cases of Covid-19 can be predicted. In order to achieve that, the performance of non-pharmaceutical interventions along with other strategies to mitigate Covid-19 is crucial in the prevention and control of infectious diseases. Non-pharmaceutical interventions include personal and environmental actions such as staying home when sick, covering coughs and sneezes, washing hands often, and routinely cleaning frequently touched surfaces [12]. Other public health measures that can slow down the transmission and spread of infectious diseases include social distancing and travel related interventions [13]. 
The presence of the COVID-19 pandemic in low- and middle-income countries (LMICs) is raising important concerns about the preparedness of health systems within these countries to address the disease as it continues to spread. Current recommendations focus heavily on hospitalbased interventions, but in the context of severe resource limitations, addressing shortages of hospital beds, oxygen, ventilators and personal protective equipment as primary response initiatives may not be realistic. Moreover, there is a need within LMICs to provide emergency support to vulnerable populations, including individuals and households experiencing poverty [14]. It is almost widely accepted that with the onset of current global drastic measures of testing, contact tracing, isolating, social distancing, and quarantining, COVID-19 can be contained, at least in its initial spread. However, the rapid acceleration of the disease in different countries and the near-collapse, if not total breakdown, of healthcare systems even in countries with more robust public health mechanisms indicate shortfalls of preparedness of countries in handling pandemics. Further elaborated that a lockdown exit strategy must carefully consider the triangulation of "the health of their citizens, the freedoms of their population, and economic constraints". These factors could be translated into three control knobs for governments: (1) isolation of patients and contact tracing, (2) border restrictions, and (3) social distancing.

The Congress of the Republic of the Philippines needs to authorize Duterte to realign P275 B to combat pandemic; the Philippine Congress, through the Bayanihan to Heal as One Act, allocates US\$ 5.37 billion for the COVID-19 pandemic, where US\$ 3.9 billion is allotted for the implementation of the emergency subsidy program, and US\$ 1.4 for funding health requirements and other services [15]. The emergency subsidy program for two months covers the basic needs of the 18 million Filipino families [16]. The strict quarantine measures have put off public and private establishments that generate more than twothirds of the overall GDP [17]. The inflation is expected to reach $2.2 \%$ in 2020 , subsequently $2.4 \%$ in 2021 according to Asian Development Bank (2020) has projected GDP growth at $2 \%$ this year, with a strong recovery forecast of $6.5 \%$ growth in 2021 with the assumption that the pandemic will be curbed in June 2020 .

The researchers are uncertain on precisely how much the public will widely adopt to the use of face masks or face shield, hand washing and social distancing during Covid-19 pandemic and adherence of the people to Covid-19 preventive measures with the aim of knowing the degree of compliance of the public to community infection control standards during Covid-19 pandemic.

\section{THE REVIEW}

\subsection{Aim}

The purpose of this review is to identify and assess the strategies utilized in conducting studies related to compliance to community infection standards during Covid-19 pandemic.

\subsection{Design}

Whittemore and Knafl's framework for integrative review assisted guided the researcher in this literature analysis. The integrative review method is the only approach that allows for the combination of diverse methodologies (i.e., experimental and non-experimental research), and has the potential to play a greater role in evidencebased practice for nursing [18]. Also, it incorporates a method of analyzing research from diverse empirical and theoretical sources and delineates a systematic framework that enhances the rigor of the integrative review process [19]. In addition, it is a specific review method that summarizes past empirical or theoretical literature to provide a more comprehensive understanding of a particular phenomenon or healthcare problem [20]. Indeed, integrative review provides a 
comprehensive perspective on the compliance to community infection standards during the Covid-19 pandemic. The process of integrative review starts with the identification of problem and other related concepts for the purpose of extracting data. Then, literatures that are relevant to the review were evaluated and once identified; data from these literatures are extracted and reduced by grouping and sub grouping concepts together. Extracted data are then arranged for the purpose of analyzing the relationships and differences among these concepts. And lastly, conclusions are formulated based on the analysis of the data gathered from relevant literatures.

\subsection{The Literature Search}

The researchers identified relevant published literatures from 3 electronic databases including PubMed, Google Scholar, and Microsoft Academic. These databases were systematically searched from October 2021 research studies that were published in the English language that discussed the compliance to community infection control during the Covid-19 pandemic. Several terms were utilized and combined to form key words. For compliance, search terms were compliance or adherence or observance. Meanwhile, for community, search terms were community or locality or locale or public. The key terms infection control includes practices such as hand washing, physical distancing, and wearing of face mask. During the process of literature search, these search terms were used, filtered by date, English language, and full-text were used, if available. The combination of these terms was used to search relevant literatures from aforementioned electronic databases. Inclusion criteria include literatures published from 2020 up to the present that was written in the English language and published in a scientific journal were included in this review. The year selected, 2020 was specifically selected based on the idea that Covid-19 was first identified. In addition, primary research studies contained aforementioned key terms. Excluded articles were those literatures that were published before 2020, published in language other than English, those research studies that did not contain aforementioned key terms, and those that did not focus on community infection control. A detailed literature search strategy resulted in 26 academic papers. After rigorous examination of these literatures, 21 relevant studies were identified. These research studies were examined and narrowed down to 11 studies.

\section{4 Data Evaluation}

Research studies were further appraised prior to being incorporated in this integrative review. Studies that were included are appraised using quality assessment tool for quantitative studies [21]. 6 research studies failed to meet the standards and therefore disregarded. These research studies contain 2 or more weak ratings based on the following component ratings: selection bias, study design, confounders, blinding, data collection method, and withdrawals and dropouts. A total of 4 studies were included all of which are quantitative studies. These 4 research studies have at least 1 weak rating or did not contain any weak rating based on the aforementioned component ratings.

Figure 1 shows that the initial search conducted by the authors yielded 26 research studies from 3 electronic databases. 5 studies were removed due to duplication $(n=5), 21$ research studies were appraised by examining the titles and abstracts for their contents. Studies that focused on compliance to community infection control standards were retained and were subjected to full-text review. These 21 studies have undergone screening for their contents and 9 of these studies did not met the inclusion criteria set by the authors $(n=11)$. The remaining literatures were retained for fulltext review and assessed by the authors. Differences were resolved after thorough discussion. Consensus on these differences 
Romeo M. Sanchez II et.al. Compliance to community infection control standards during the COVID-19 pandemic: an integrative review.

was resolved and 4 studies were included in this integrative review
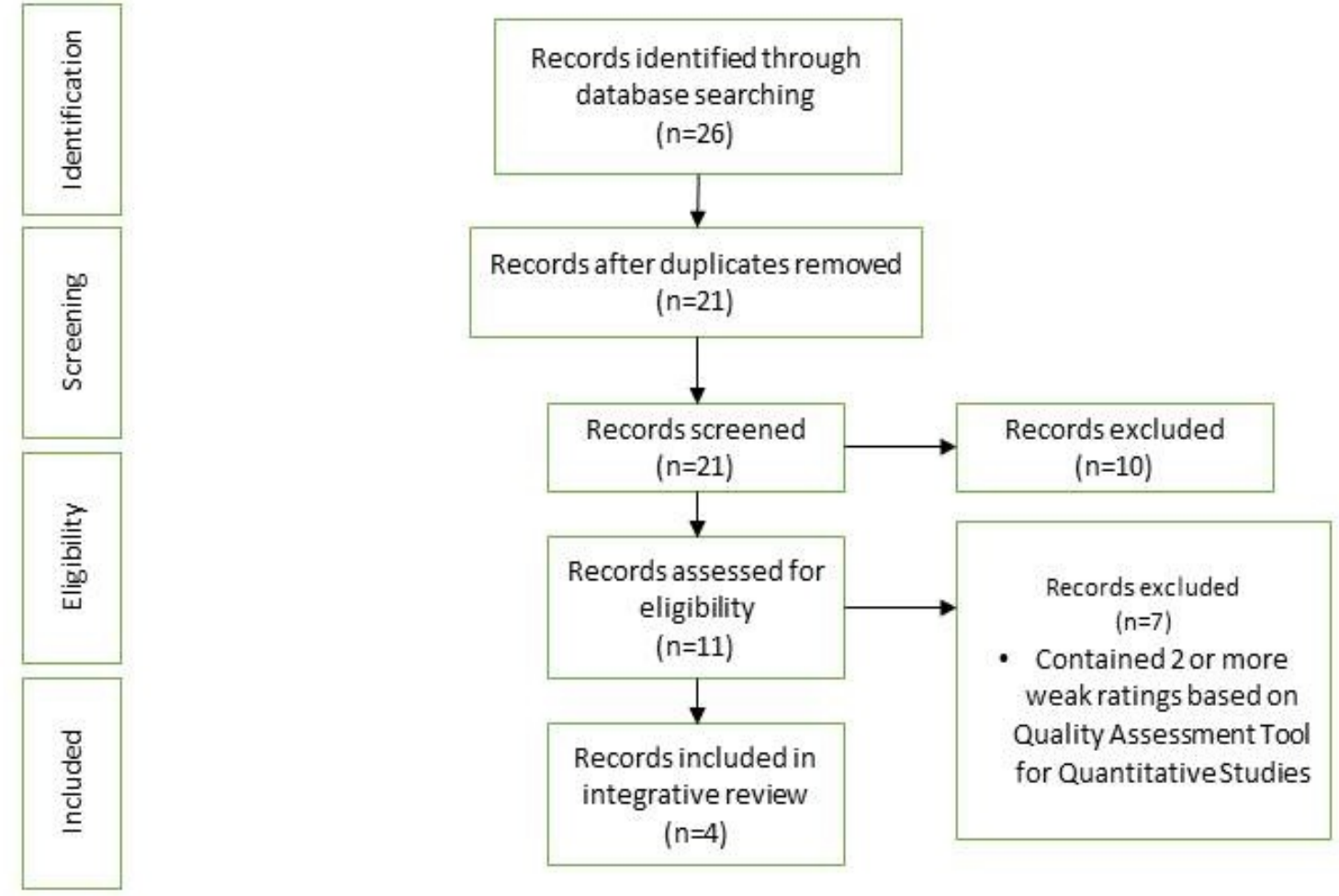

Figure 1: PRISMA Flow Diagram

\section{QUALITY APPRAISAL}

Validated appraisal tool such as Quality Assessment Tool for Quantitative Studies [21] is recommended to use in completing integrative review. It assists the researchers in evaluating the quality of research studies prior to being included in the review. Research studies that are subjected to this review were scored on the global rating based on individual component ratings as follows: selection bias, study design, confounders, blinding, data collection method, withdrawals and dropouts. Each literature is appraised using these component ratings and rated with a score of 1 for strong, 2 considered to be moderate, and 3 as weak ratings. The quality appraisal indicated that studies included in this review were moderate quality.

\begin{tabular}{|c|c|c|c|c|}
\hline $\begin{array}{c}\text { Citation \& } \\
\text { Country }\end{array}$ & Aim & Site and Subject & Method & $\begin{array}{c}\text { Quality } \\
\text { Appraisal }\end{array}$ \\
\hline $\begin{array}{l}\text { Wang, Q. et. } \\
\text { al., 2020; } \\
\text { China }\end{array}$ & $\begin{array}{l}\text { To examine the secondary transmission of severe } \\
\text { acute respiratory syndrome coronavirus } 2 \text { (SARS- } \\
\text { CoV-2) within the family. }\end{array}$ & $\begin{array}{l}\text { Participants }(\mathrm{n}=335) \text { in } 124 \\
\text { families and with at least one } \\
\text { laboratory confirmed COVID- } \\
19 \text { case in Beijing, China. }\end{array}$ & $\begin{array}{l}\text { Retrospective } \\
\text { cohort study }\end{array}$ & Moderate \\
\hline $\begin{array}{l}\text { Winters, M. } \\
\text { et. a., 2020; } \\
\text { Sierra Leone }\end{array}$ & $\begin{array}{l}\text { To assess the public's knowledge, attitudes and } \\
\text { practices about the Covid-19 virus in and to inform } \\
\text { an evidence-based communication strategy around } \\
\text { Covid-19. }\end{array}$ & $\begin{array}{l}\text { Randomly selected } \\
\text { communities in all } 14 \text { districts } \\
\text { in Sierra Leone. }\end{array}$ & $\begin{array}{l}\text { Cross-sectional } \\
\text { study }\end{array}$ & Moderate \\
\hline $\begin{array}{l}\text { Zhang, J. et. } \\
\text { al., 2020; } \\
\text { China }\end{array}$ & $\begin{array}{l}\text { It aims to understand the knowledge, attitudes and } \\
\text { practices of COVID-19 in the Chinese context and } \\
\text { to provide insights for developing targeted outbreak } \\
\text { prevention and control measures among the general } \\
\text { public. }\end{array}$ & $\begin{array}{l}\text { People aged } 15 \text { years or older } \\
\text { with access to the computer } \\
\text { and/or mobile phone }(n=517) \text { in } \\
\text { Henan Province, China }\end{array}$ & $\begin{array}{l}\text { Cross-sectional } \\
\text { study }\end{array}$ & Moderate \\
\hline $\begin{array}{l}\text { Zarei, N. et. } \\
\text { al., 2021; Iran }\end{array}$ & $\begin{array}{l}\text { aimed to investigate the knowledge and preventive } \\
\text { practices of Iranians toward the COVID-19 } \\
\text { pandemic }\end{array}$ & $\begin{array}{l}\text { people older than age } 10 \text { years } \\
\text { who had access to the Internet } \\
(n=925) \text { in Iran }\end{array}$ & $\begin{array}{l}\text { Cross-sectional } \\
\text { study }\end{array}$ & Moderate \\
\hline
\end{tabular}




\section{DISCUSSION}

The four research studies that were included in the review were undertaken within China $(n=2)$, Iran $(n=1)$, and Sierra Leone $(n=1)$. Two studies focused on the prevention and control of Covid-19 on the personal level, one in the family setting, and one in the participants' locality. After data synthesis, multiple factors were identified. Data were categorized into themes.

\subsection{Effective infection control practices.}

This theme refers to the practices in which the respondents of the studies perform in order to prevent and control the spread of Coivd-19 in the community setting. Infection control practices that are essential in the prevention and control of Covid-19 on the personal level were the use of N95 masks/disposable surgical masks, hand washing using 7-step protocol, and covering of nose and mouth with paper tissues or elbows while coughing and sneezing as well as leaving the house only when necessary, not shaking hands with, or kissing or hugging others, and disinfecting handles and surfaces [22, 23]. Meanwhile, the health practices in the households in the prevention and control of Covid-19 include the use of face masks, physical distancing, frequent room cleaning once in 1-2 days, frequent house cleaning using chlorine or ethanol-based disinfectant once in 2 or more days, and the practice of opening the windows to allow convection of indoor air of more than one per day [24]. And for community-wide infection prevention and control practices against Covid-19, custom habits include hand washing with soap and water and avoiding crowded places [25]. It is important that the community should focus on the preventive aspects of mitigating Covid-19 instead of the curative aspect. Without any pharmaceutical intervention and vaccination, the only way to combat Coronavirus Disease 2019 (COVID-19) is to slow down the spread of the disease by adopting non-pharmaceutical public health interventions (PHIs). Patient isolation, lockdown, quarantine, social distancing, changes in health care provision, and mass screening are the most common non-pharmaceutical PHIs to cope with the epidemic [26]. The responses of the participants were aligned with the recommendations of the World Health Organization in mitigating Covid-19. To ensure good hygiene, it is essential to wear mask properly, make the environment safe, and keep good hygiene by regularly and thoroughly cleaning of hands with either an alcohol-based hand rub or soap and water and cleaning and disinfecting surfaces frequently, especially those which are regularly touched, such as door handles, faucets and phone screens. Also, covering the mouth and nose with your bent elbow or a tissue when you cough or sneeze and dispose of the used tissue immediately into a closed bin and wash your hands is important in controlling the spread of Covid-19 [27]. The performance of these essential health practices will therefore help in the mitigation of Covid-19.

\subsection{Factors affecting compliance}

This theme enumerates the reasons that affect the compliance of the community towards covid-19 prevention and control. The studies that were included in this review discussed the direct correlation of adequate knowledge in the practice and compliance towards Covid-19 mitigation $[23,25]$. Factors such as age, gender, occupational status, education, availability of hand sanitizers, gloves, masks, cost of hand sanitizers, and belief in the effectiveness of using such necessities were significantly associated with the practice of preventive measures reading the virus [23]. In addition, people residing in urban areas are more compliant to Covid-19 infection prevention and control as people living in urban areas were more likely to seek medical advice than people in rural areas if they suspected infection [22]. Further, individuals and community compliance with these measures will define how long a country will be in a risky zone before gradually reaching the new normal. 
However, governments could impose various measures, such as arresting those violating curfew and social distancing measures [28]. Modifiable factors such as education and accessibility of hygiene products must be the government and health authority's priority in ensuring that preventable measures are taken into actions. Rigorous health information dissemination and provision of hygiene products are essential in insuring that people in the community will comply with preventive measures that help mitigate Covid-19. It is vital in the prevention of spread of the infection.

In the current study, we summarized our implementation of various strategies and measurements to prevent and control COVID-19 infection in four research studies that were included in the review. The prevention and control measurements included effective infection control practices, factors affecting compliance and city-wide orders to close workspaces, sanitize essential workspaces, quarantine individuals with a travel history to an epidemic area, and issue emergency medical responses to quarantine and treat COVID-19 patients using all necessary technologies, personnel, and resources. Strategies in the control of an outbreak are screening, containment (or suppression), and mitigation. Screening is done with a device such as a thermometer to detect the elevated body temperature associated with fevers caused by the coronavirus. Containment is undertaken in the early stages of the outbreak and aims to trace and isolate those infected as well as introduce other measures to stop the disease from spreading [30]. When it is no longer possible to contain the disease, efforts then move to the mitigation stage: measures are taken to slow the spread and mitigate its effects on the healthcare system and society. A combination of both containment and mitigation measures may be undertaken at the same time. Suppression requires more extreme measures so as to reverse the pandemic by reducing the basic reproduction number. The lessons learned from our response include the following: (1) Issue city-wide orders to close workspaces or reduce operation hours for essential facilities, like public water, gas, or telecommunication facilities, medical staff, and supermarkets. (2) Enforce social distancing. (3) Enforce body temperature checks and DNA testing, when feasible. (4) Everyone wears a facemask. (5) Quarantine and isolate individuals with a travel history to an epidemic area and who have COVID19-like symptoms [31].

\section{CONCLUSIONS}

The researchers conclude that despite having enough knowledge and awareness on the various information regarding the existence of the Coronavirus disease, the people in the community still need to enhance their knowledge along COVID 19 issues to minimize the risk of having the virus. Minimizing the risk of getting the virus would also mean minimizing the risk of infecting other people in their community with the said virus.

In the primary health system, those who play important roles in the community, such as health volunteers, barangay officials and people in every area, will be an important force to help prevent the disease's spread. The participation of people in the community is rationale with the situation of the community concept and it can enable the people to work faster, resulting in the creation of better health care systems, providing better social services, and improving the economy.

On the basis of the findings and conclusion drawn, the researcher hereby recommends additional preventive strategies to safeguard populations at highest risk for severe outcomes from COVID-19, particularly in the context of the highly transmissible Delta variant. Unvaccinated persons remain at risk for infection, severe illness, and death. Advanced age, pregnancy, and an increasingly well-defined set of underlying medical conditions increase the risk for serious outcomes from 
COVID-19 among unvaccinated persons. Further, unvaccinated persons should continue following all prevention strategies, including wearing a mask, until they are fully vaccinated. Immunocompromised persons should continue to take all recommended precautions until advised otherwise by their health care provider. Lastly, health care providers who are trained in preventing COVID 19 transmission should conduct seminars in the people of the community for them to update their knowledge and practices in proper way to minimize the risk of having the virus.

\section{RECOMMENDATIONS FOR RESEARCH, PRACTICE, AND EDUCATION}

\subsection{Research}

The authors recommend that more nurse researchers should invest in a culture study that prioritizes safety and infection prevention and control, and offer adequate resources (e.g., experience, financing, staff, supplies, and information technology) to incorporate infection control and prevention features

\subsection{Practice}

The authors recommend that health services review information about infectious risks, exposures, and illnesses on a regular basis; conduct regular risk assessments and risk reduction activities related to community infection prevention and control, or collaborate with other healthcare organization departments or individuals. In addition, meet with health-care officials on a regular basis to discuss the results of risk assessments linked to community infection prevention and control, define performance targets, and assign risk reduction responsibilities to appropriate healthcare organization departments and personnel.

\subsection{Education}

This research study will aid Nursing Education to develop a systematic and knowledgeable teaching style that shares information and experiences of people in the
COVID-19 places during the pandemic. The study can also be useful in teaching and assisting learners or other student nurses about the factors that affects compliance to infection control standards among people in the community. Furthermore, for the nursing students to also conduct a study that is more relevant to the topic. In addition, this is beneficial as it shows that nurses engage in lifelong learning through the full extent of their education and training. This is important in determining how a nurse's knowledge, attitude, and skills change as they execute nursing practice. Moreover, in the provision of learning opportunities, the health and safety of the learners and even non-teaching personnel are an utmost importance and must be protected at all times [29].

\section{LIMITATIONS}

A limitation of this review is the small number of included publications may be due to the novelty of the research topic. Secondly, related to the novelty of the topic, the importance of submitting one's self for Covid-19 vaccination was not discussed among the research studies that have been included in this review. Vaccination is now considered as one of the essential components in the prevention and control of Covid-19.

\section{Acknowledgement: None}

\section{Conflict of Interest: None}

\section{Source of Funding: None}

Ethical Approval: Not required

\section{REFERENCES}

1. Carrico, R., Garrett, H., Balcom, D., \& Glowicz, JB. (2018). Infection Prevention and Control Core Practices: A Roadmap for Nursing Practice. Retrieved from https://www.ncbi.nlm.nih.gov/pmc/articles/ PMC6290992/ on September 20, 2021.

2. World Health Organization. WHO Coronavirus (COVID-19) Dashboard. 
Romeo M. Sanchez II et.al. Compliance to community infection control standards during the COVID-19 pandemic: an integrative review.

Retrieved from https://covid19.who.int/ on September 20, 2021.

3. Haleem, A. \& Javaid, M. (2020). Effects of COVID-19 pandemic in daily life. Retrieved from

https://www.ncbi.nlm.nih.gov/pmc/articles/ PMC7147210/ on September 20, 2021.

4. Lofti, M., Hamblin, M., \& Rezaei, N. (2020). COVID-19: Transmission, prevention, and potential therapeutic opportunities. Retrieved from https://www.ncbi.nlm.nih.gov/pmc/articles/ PMC7256510/ on September 20, 2021.

5. Petrosillo, N., Viceconte, G., Ergonul, O., Ippolito, G., \& Petersen, E. (2020). COVID19, SARS, and MERS: are they closely related? Retrieved from https://pubmed.ncbi.nlm.nih.gov/32234451 on October 3, 2021.

6. Wilder-Smith, A., Chiew, C.J., \& Lee, V.J. (2020). Can we contain the COVID-19 outbreak with the same measures as for SARS? Lancet Infect Dis, 2020; e102-07. Retrieved from https://doi.org/10.1016/S14733099(20)30129-8 on October 2, 2021.

7. Pescarini, J.M., Silveira, I.H., Souza-Filho, J.A. et. al. (2020). Covid-19 in Latin American Countries: Course of the pandemic and the different responses towards control, Retrieved from https://doi.org/10.21203/rs.3.rs-56504/v1 on September 30, 2021.

8. 8 . Storr, J., Twyman, A., Zingg, W., Damani, N., Kilpatrick, C., Reilly, J., Price, L., Egger, M., grayson, ML., Kelley, E., Allegranzi, B., \& the WHO Guidelines Development Group (2017). Core components for effective infection prevention and control programmes: new WHO evidence-based recommendations. Retrieved from https://aricjournal.biomedcentral.com/article s/10.1186/s13756-016-0149-9 on September 20, 2021.

9. World Health Organization (2020). Transmission of SARS-CoV-2: implications for infection prevention precautions. Retrieved from https://www.who.int/newsroom/commentaries/detail/transmission-ofsars-cov-2-implications-for-infectionprevention-precautions on September 20, 2021.

10. Public Health England (2021). SARS-CoV2 variants of concern and variants under investigation in England-technical briefing 17. Retrieved from https://assets.publishing.service.gov.uk/gove rnment/uploads/system/uploads/attachment_ data/file/997418/Variants_of_Concern_VO C_Technical_Briefing_17.pdf on September 20, 2021.

11. World Health Organization (2021). Infection prevention and control. Retrieved from https://www.who.int/healthtopics/infection-prevention-and-

control\#tab=tab_1 on September 24, 2021.

12. Center for Disease Control and Prevention. Community Interventions for Infection Control. Retrieved from https://www.cdc.gov/ncezid/dgmq/focusareas/ciic.html on September 24, 2021.

13. World Health Organization (2020). Responding to community spread of COVID-19. Interim guidance. Retrieved from

https://apps.who.int/iris/bitstream/handle/10 665/331421/WHO-COVID-19-

Community_Transmission-2020.1-eng.pdf on September 24, 2021.

14. Lau, L., Hung, N., Go, D., Ferma, J., Choi, M., Dodd, W., \& Wei, X. (2020). Knowledge, Attitudes and Practices of Covid-19 among income poor households in the Philippines: A Cross-sectional Study. Retrieved from https://dx.doi.org/10.7189\%2Fjogh.10.0110 07

15. Atienza, L. C. (2020). Manila Bulletin. Congress needs to authorize Duterte to realign P275 B to combat pandemic. Retrieved from https://news.mb.com.ph/2020/03/23/villafue rte-congress-needs-to-authorize-duterte-torealign-p275-b-to-combat-pandemic/ on September 30, 2021.

16. Vitangcol, A. (2020). Social amelioration program should be for everyone, but in reality it's not. Manila Bulletin. Retrieved from

https://www.manilatimes.net/2020/04/11/op inion/columnists/social-ameliorationprogram-should-be-for-everyone-but-inreality-its-not/712356/ on September 30, 2021.

17. Asian Development Bank (2020). Philippine GDP growth to slide in 2020 due to COVID-19, strong rebound seen in 2021 ADB. Retrieved from https://www.adb.org/news/philippine-gdp- 
Romeo M. Sanchez II et.al. Compliance to community infection control standards during the COVID-19 pandemic: an integrative review.

growth-slide-2020-due-covid-19-strongrebound-seen-2021-adb on September 30, 2020.

18. Whittemore, R. and Knafl, K. (2005). The integrative review: updated methodology. Retrieved from https://onlinelibrary.wiley.com/doi/10.1111/ j.1365-2648.2005.03621.x on September 26, 2021.

19. Whittemore, R. and Knafl, K. (2005). The integrative review: updated methodology, Journal of Advanced Nursing, vol. 52, no. 5, pp. 546-553, 2005.

20. Broome M.E. (1993). Integrative literature reviews for the development of concepts. In Concept Development in Nursing, 2nd edn (Rodgers B.L. \& Knafl K.A., eds), W.B. Saunders Co., Philadelphia, PA, pp. 231250

21. Effective Public Healthcare Panacea Project. (2021). Quality Assessment Tool for Quantitative Studies. Retrieved from https://www.ephpp.ca/quality-assessmenttool-for-quantitative-studies/ on October 5, 2021.

22. Yue, S.T., Zhang, J., Cao, M., \& Chen, B. (2020). Knowledge, Attitudes and Practices of COVID-19 Among Urban and Rural Residents in China: A cross-sectional study. Retrieved from https://www.ncbi.nlm.nih.gov/pmc/articles/ PMC7403196/ on October 18, 2021.

23. Heydari, M.R., Joulaei, H., Zarei, N., Fararouei, M., \& Gheibi, Z. (2021). An Online Investigation of Knowledge and Preventive Practices in Regard to COVID19 in Iran. Retrieved from https://www.ncbi.nlm.nih.gov/pmc/articles/ PMC7801262/ on ocotber 18, 2021.

24. Wang, Q. et. al. (2020). Reduction of secondary transmission of SARS-CoV-2 in households by face mask use, disinfection and social distancing: a cohort study in Beijing, China. Retrieved from https://gh.bmj.com/content/5/5/e002794 on October 18, 2021.

25. Sengeh, P., Jalloh, M., Webber, N., Ngobeh, I., Samba, T., Thomas, H., Nordenstedt, H., \& Winters, M. (2020). Community knowledge, perceptions, and practices around COVID-19 in Sierra Leone: a nationwide, cross-sectional survey. Retrieved from https://bmjopen.bmj.com/content/10/9/e040 328 on October 18, 2021.

26. Lezadi, S., Azami-Aghdash, S., Ghiasi, A., Rezapour, A., Pourasghari, H., Pashazadeh, F., \& Gholipour, K. (2020). Effectivenss of the non-pharmaceutical public health interventions against COVID-19; a protocol of a systematic review and realist review. Retrieved from https://journals.plos.org/plosone/article?id= 10.1371/journal.pone.0239554 on October 18, 2021.

27. World Health Organization (2021). Advice for the public: Coronavirus disease (COVID-19). Retrieved from https://www.who.int/emergencies/diseases/n ovel-coronavirus-2019/advice-for-public on October 21, 2021.

28. Alshammari, A., Alshammari, H., \& Alshammari, S. (2021). Factors associated with Adherence to COVID-19 Preventive Measures Among Saudi Arabians. Retrieved from

https://www.cureus.com/articles/43661factors-associated-with-adherence-to-covid19-preventive-measures-among-saudiarabians on October 18, 2021.

29. Department of Education - Philippines (2020). Guidelines on the Required Health Standards in Basic Education Offices and Schools. Retrieved from https://www.deped.gov.ph/wpcontent/uploads/2020/06/DO_s2020_014.pd f on October 21, 2021.

30. Ramphul K, Mejias SG. Coronavirus disease: a review of a new threat to public health. Cureus. (2020) 12:e7276. doi: 10.7759/cureus.7276 PubMed Abstract | CrossRef Full Text | Google Scholar

31. Huang C, Wang Y, Li X, Ren L, Zhao J, Hu $\mathrm{Y}$, et al. Clinical features of patients infected with 2019 novel coronavirus in Wuhan, China. Lancet. (2020)395:497-506. doi:10.1016/S0140-6736(20)30183-5

How to cite this article: Romeo M. Sanchez II, Soriano GR, Sheree Ann A. Ortua et.al. Compliance to community infection control standards during the COVID-19 pandemic: an integrative review. Int J Health Sci Res. 2021; 11(11): 296-305. DOI: https://doi.org/10.52403 /ijhsr.20211135 